\title{
The Journal of Antibiotics partners with Nature Publishing Group
}

The Journal of Antibiotics (2009) 62, 3; doi:10.1038/ja.2008.14

T $\mathrm{t}$ is our great pleasure and honor to announce to our readers our 1 new publishing partnership with Nature Publishing Group (NPG), a renowned international science publisher, to publish The Journal of Antibiotics (JA) from January 2009.

The new partnership between NPG and the Japan Antibiotics Research Association (JARA) to publish $J A$ is an exciting development and will greatly enhance the visibility and impact of $J A$ - and help to establish the journal as one of the leading bioactive and microbial natural products journals.

Under the leadership of Editor-in-Chief Dr Satoshi Ōmura, we foresee a close and fruitful collaboration among the vital elements of a successful journal. These elements include the Association and publishers, Editorial Board members, reviewers, and of course our authors. The outcome of this collaboration will ensure the high quality of $J A$, increase the international standing of the journal, and will, I believe, fulfill some of the aims of JARA: to serve the research community by publishing a journal with the highest quality and with high impact in the field of bioactive and microbial natural products research.

Jingoro Shimada

President

Japan Antibiotics Research Association, Japan E-mail: gakkyo@antibiotics.or.jp 